Jurnal PRIMATIKA, Volume 8, Nomor 2, Desember 2019

\title{
PENGARUH INTERAKSI SOSIAL DAN BERPIKIR KRITIS TERHADAP HASIL BELAJAR MATEMATIKA SISWA KELAS VIII SMP NEGERI 1 SAMARINDA
}

\author{
Pratiwi Kurnia Sari \\ Sugeng ${ }^{1)}$ \\ ${ }^{1)}$ Dosen Pendidikan Matematika FKIP Universitas Mulawarman \\ Email: sugeng@fkip.unmul.ac.id
}

\begin{abstract}
ABSTRAK
Penelitian ex post facto ini bertujuan untuk mengetahui pengaruh interaksi sosial $\left(X_{1}\right)$, dan berpikir kritis $\left(X_{2}\right)$ terhadap hasil belajar matematika $(Y)$ siswa kelas VIII SMPN 1 Samarinda tahun ajaran 2017/2018. Populasi penelitian ini adalah seluruh siswa kelas VIII yang terdiri dari 11 kelas dengan jumlah 351 siswa. Sampel penelitian berukuran 187 siswa (atau 6 kelas) yang ditentukan dengan teknik cluster random sampling. Penelitian ini menggunakan instrumen angket dan tes. Sebelum digunakan untuk penelitian, kedua instrumen diujicobakan dan hasilnya 30 butir angket interaksi sosial, 5 soal berpikir kritis, dan 7 soal hasil belajar matematika dinyatakan valid. Analisis data menggunakan statistik deskriptif dan statistik inferensial dengan taraf signifikan $(\alpha)=5 \%$. Hasil analisis deskriptif menunjukkan variabel interaksi sosial dan berpikir kritis berkategori sedang dan rata-rata hasil belajar matematika $(\bar{x}=50,92)$ juga berkategori sedang. Hasil analisis inferensial menggunakan regresi linear ganda diperoleh persamaan regresi dugaan, yaitu $\hat{Y}=$ $-54,172+0,872 X_{1}+0,554 X_{2}$, dengan $\mathrm{F}_{\text {hit }}=43,433$, dan nilai probabilitas (sig. Uji $F$ ) sebesar 0,000 sehingga diperoleh model regresi dapat dipakai untuk memprediksi hasil belajar matematika. Kontribusi interaksi sosial dan berpikir kritis terhadap hasil belajar matematika sebesar $32,1 \%$ (atau $R^{2}=0,321$ ). Untuk variabel interaksi sosial dan variabel berpikir kritis, masing-masing diperoleh nilai dari probabilitas (sig. Uji $t$ ) sebesar 0,000 . Dengan demikian, interaksi sosial dan berpikir kritis masing-masing berpengaruh terhadap hasil belajar matematika.
\end{abstract}

Kata kunci: Interaksi Sosial, Kemampuan Berpikir Kritis, Hasil Belajar Matematika

\begin{abstract}
This ex post facto research aims to determine the effect of social interaction, and critical thinking on mathematics learning outcomes of VIII grade students of SMPN 1 Samarinda in the academic year 2017/2018. The population of this study was all students of class VIII consisting of 11 classes with a total of 351 students. The sample size of 187 students (or 6 classes) was determined by cluster random sampling technique. This study uses a questionnaire and test instruments. Before being used for research, the two instruments were trialled and the results were 30 items of social interaction questionnaire, 5 questions of critical thinking, and 7 questions of mathematics learning outcomes were declared valid. Data analysis uses descriptive statistics and inferential statistics with a significance level of $5 \%$. The results of the descriptive analysis show the variables of social
\end{abstract}


interaction and critical thinking in the medium category; and the average mathematical learning outcomes $(\bar{x}=50,92)$ are also in the medium category. The results of inferential analysis using multiple linear regression obtained by the estimated regression equation, that is $\widehat{Y}=-54,172+0,872 X_{1}+0,554 X_{2}$ with $\mathrm{F}_{\text {hit }}=43.433$ and the probability value (sig. Ftest) of 0,000 so that the estimated regression model is meaningful or can be used to predict mathematics learning outcomes. The contribution of social interaction and critical thinking to mathematics learning outcomes is $32.1 \%$ (or $\mathrm{R}^{2}=0.321$ ). For social interaction variables and critical thinking variables, each obtained a probability value (sig. t- test) of 0,000 . This, social interaction and critical thinking each affect the learning outcomes of mathematics.

Keywords: Social Interaction, Critical Thinking Ability, Mathematics Learning Outcomes

\section{PENDAHULUAN}

Dunia pendidikan sedang dihadapkan pada tantangan untuk melahirkan individu yang dapat memenuhi tuntutan global. Hal ini dikarenakan berbagai berita dapat diakses dengan bebas melalui jaringan internet dan belum ada jaminan bahwasannya berita tersebut benar, sehingga setiap individu harus memiliki kemampuan memilah antara benar dan salah. Salah satu kemampuan yang harus dimiliki oleh setiap individu dalam menghadapi hal tersebut adalah kemampuan berpikir kritis.

Berdasarkan Standar Isi dalam Permendiknas Nomor 22 Tahun 2006, mata pelajaran matematika merupakan salah satu mata pelajaran yang diberikan untuk membekali peserta didik dengan kemampuan berpikir ilmiah secara kritis, kreatif dan mandiri. Kompetensi tersebut diperlukan agar siswa dapat memiliki kemampuan memperoleh, mengelola, dan memanfaatkan informasi untuk bertahan hidup pada keadaan yang selalu berubah, tidak pasti, dan kompetitif.

Berdasarkan nilai rata-rata matematika pada ulangan semester ganjil siswa kelas VIII SMPN 1 Samarinda, dari sebelas kelas yang ada hanya dua kelas saja yang memenuhi standar ketuntasan belajar, yaitu kelas VIII $_{A}$ dan VIII $_{B}$. Hal ini tentu menjadi hal yang serius untuk siswa dan guru mengingat SMPN 1 Samarinda merupakan salah satu sekolah favorite di Samarinda dan memiliki standar ketuntasan belajar yang tinggi yaitu 80 .

Bervariasinya nilai rata-rata siswa kelas VIII tersebut, dipengaruhi oleh banyak hal seperti yang sudah dipaparkan di atas mengenai faktor-faktor yang mempengaruhi hasil belajar yang terdiri dari faktor internal dan faktor eksternal. Faktor internal yang mempengaruhi beragamnya nilai siswa salah satunya adalah kemampuan siswa untuk berpikir kritis dalam menyelesaikan soal-soal matematika yang diberikan oleh guru. Sedangkan salah satu faktor eksternal yang mempengaruhinya yaitu interaksi sosial siswa, baik dengan sesama teman, dengan guru yang bersangkutan, maupun interaksi siswa dengan keluarga atau masyarakat.

Bentuk umum proses sosial adalah interaksi sosial, karena interaksi sosial merupakan syarat utama terjadinya aktivitas-aktivitas sosial. Bentuk lain dari proses sosial hanya merupakan bentukbetuk khusus dari interaksi sosial 
(Soerjono, 2012). Interaksi sosial yang dikemukakan oleh Effendi dan Ridwan (2011), memuat arti bahwa interaksi sosial merupakan proses dimana orang-orang berkomunikasi saling mempengaruhi dalam pikiran dan tindakan. Maksud saling mempengaruhi ini adalah bahwa dalam setiap komunikasi antara manusia akan terjadi proses pertukaran pendapat, saling merespon satu sama lain sehingga dari hasil respon itu dapat mempengaruhi pikiran orang yang saling berkomunikasi.

Iskandar (2009), mengemukakan bahwa kemampuan berpikir kritis merujuk pada pemikiran seseorang dalam menilai kevalidan dan kebaikan suatu ide, buah fikiran, pandangan dan dapat memberi respons berdasarkan kepada bukti dan sebab akibat. Adapun jenis-jenis pemikiran kritis seperti membandingkan dan membeda (comparendecontrast), membuat kategori (categorization), menerangkan sebab akibat (cause and effect), meneliti bagian dan hubungan bagian kecil dengan keseluruhan, membuat andaian, membuat ramalan dan inferensi. keterampilan berpikir, maupun keterampilan motorik. Di sekolah hasl belajar ini dapat dilihat dari penugasan siswa akan mata pelajaran yang ditempuhnya. Tigkat penugasan pelajaran atau hasil belajar dalam mata pelajaran terebut di sekolah dilambangkan dengan angka atau huruf, seperti 0-100 atau huruf $\mathrm{A}, \mathrm{B}, \mathrm{C}$, atau D. Alat untuk mengukur hasil belajar disebut tes hasil belajr atau tes prestasi belajar atau achievement test (Syaodih dan Sukmadinata, 2009).

\section{METODE PENELITIAN}

Jenis penelitian ini adalah penelitian ex post facto yang bertujuan untuk mencari hubungan sebab-akibat dengan cara membandingkan dua atau lebih kelompok subyek berbeda guna mengukur variabel yang sama melalui penyelidikan empiris yang sistematis; peneliti tidak mengendalikan variabel bebas secara langsung karena perwujudan variabel tersebut telah terjadi. Rancangan penelitian yang digunakan adalah

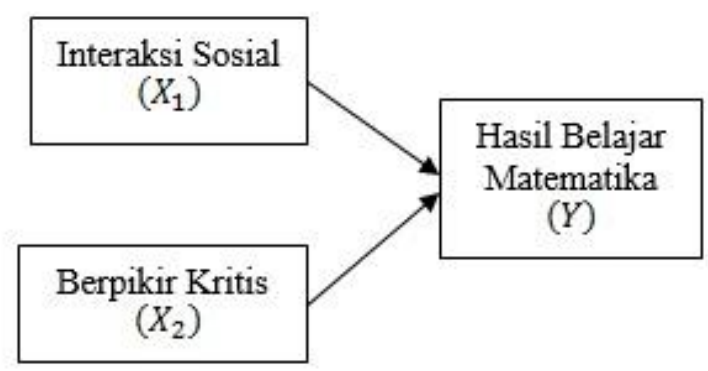

Gambar 1. Model rancangan penelitian

Hasil belajar merupakan realisasi atau pemekaran dari kecakapan-kecakapan potensial atau kapasitas yang dimiliki seseorang. Penguasaan hasil belajar dapat dilihat dari perilakunya, baik perilaku dalam bentuk penugasan pengetahuan,
Penelitian ini dilaksanakan pada semester ganjil bulan Juli-Agustus 2018 di SMPN 1 Samarinda tahun ajaran 2017/ 2018. Populasi penelitian ini adalah siswa kelas VIII berjumlah 351 siswa yang terbagi ke dalam 11 kelas. Pengambilan 
sampel dalam penelitian ini menggunakan teknik cluster random. Sedangkan teknik pengumpulan data menggunakan angket dan tes.

Teknik analisis data yang digunakan dalam penelitian ini adalah statistik deskriptif dan inferensial. Sebelum pengujian hipotesis terlebih dahulu dilakukan uji asumsi yang terdiri dari uji normalitas, uji homogenitas, uji linearitas, dan uji multikolonieritas. Setelah pengujian asumsi terpenuhi, kemudian menguji hipotesis penelitian menggunakan analisis regresi ganda.

HASIL PENELITIAN DAN PEMBAHASAN

\section{A. Hasil Penelitian}

1. Statistik Deskriptif
Data variabel interaksi sosial pada penelitian ini diukur menggunakan angket berjumlah 30 butir pernyataan. Deskripsi data variabel dapat dilihat pada tabel 1 . Hasil analisis menunjukkan bahwa skor interaksi sosial lebih banyak pada kategori sedang. Rata-rata skor angket interaksi sosial siswa yaitu 90,27 berada pada kategori sedang.

Data variabel berpikir kritis ini diukur menggunakan tes dengan butir soal berjumlah 5 soal uraian. Deskripsi data atas variabel berpikir kritis dapat dilihat pada tabel 2. Hasil analisis menunjukkan bahwa skor berpikir kritis lebih banyak pada kategori sedang. Rata-rata skor berpikir kritis siswa $(47,63)$ berada pada kategori sedang.

Data variabel hasil belajar matematika

Tabel 1. Distribusi skor variabel interaksi sosial

\begin{tabular}{|c|c|c|c|}
\hline \multicolumn{2}{|c|}{ Skor Interaksi Sosial } & \multirow{2}{*}{$\begin{array}{l}\text { Frekuensi } \\
\text { (F) }\end{array}$} & \multirow{2}{*}{$\begin{array}{c}\text { Persentase } \\
(\%)\end{array}$} \\
\hline Interval & Kategori & & \\
\hline$X \leq 77$ & Sangat Rendah & 17 & 9,1 \\
\hline $77<X \leq 85$ & Rendah & 34 & 18,2 \\
\hline $85<X \leq 94$ & Sedang & 76 & 40,6 \\
\hline $94<X \leq 103$ & Tinggi & 51 & 27,3 \\
\hline$X>103$ & Sangat Tinggi & 9 & 4,8 \\
\hline \multicolumn{2}{|c|}{ Jumlah } & 187 & 100 \\
\hline
\end{tabular}

(Sumber: Hasil penelitian 2019)

Tabel 2. Distribusi skor variabel berpikir kritis

\begin{tabular}{|c|c|c|c|}
\hline \multicolumn{2}{|c|}{ Skor } & $\begin{array}{c}\text { Frekuensi } \\
(\mathbf{F})\end{array}$ & $\begin{array}{c}\text { Persentase } \\
(\boldsymbol{\%})\end{array}$ \\
\hline$X \leq 12,6$ & Kategori & 10 & 5,3 \\
\hline $12,6<X \leq 35,9$ & Rendah & 52 & 27,8 \\
\hline $35,9<X \leq 59,2$ & Sedang & 59 & 31,6 \\
\hline $59,2<X \leq 82,5$ & Tinggi & 54 & 28,9 \\
\hline$X>82,5$ & Sangat Tinggi & 11 & 6,4 \\
\hline \multicolumn{2}{|c|}{ Jumlah } & 187 & 100 \\
\hline
\end{tabular}

(Sumber: Hasil penelitian 2019) 
ini diukur menggunakan tes dengan butir soal berjumlah 7 soal uraian. Deskripsi data variabel hasil belajar matematika terlihat pada tabel 3. Hasil analisis menunjukkan bahwa skor hasil belajar matematika lebih banyak pada kategori sedang. Rata-rata skor tes hasil belajar matematika siswa yaitu 50,96 berada pada kategori sedang.
Pengujian homogenitas data dilakukan dengan melihat hasil Scatter Plot Dependent Variable dan uji BPG (Breusch -Pagan Godfrey). Berdasarkan hasil plot residual terhadap variabel terikat menghasilkan pola diagram Hasil analisis data pada Scatter Plot Dependent Variable me-

Tabel 3. Distribusi skor variabel hasil belajar matematika

\begin{tabular}{|c|c|c|c|}
\hline \multicolumn{2}{|c|}{ Skor Interaksi Sosial } & \multirow{2}{*}{$\begin{array}{l}\text { Frekuensi } \\
\text { (F) }\end{array}$} & \multirow{2}{*}{$\begin{array}{c}\text { Persentase } \\
(\%)\end{array}$} \\
\hline Interval & Kategori & & \\
\hline$X \leq 12,3$ & Sangat Rendah & 15 & 8,0 \\
\hline $12,3<X \leq 38,1$ & Rendah & 49 & 26,2 \\
\hline $38,1<X \leq 63,9$ & Sedang & 66 & 35,3 \\
\hline $63,9<X \leq 89,7$ & Tinggi & 40 & 21,4 \\
\hline$X>89,7$ & Sangat Tinggi & 17 & 9,1 \\
\hline \multicolumn{2}{|c|}{ Jumlah } & 187 & 100 \\
\hline
\end{tabular}

(Sumber: Hasil penelitian 2019)

2. Satistik Inferensial

a. Uji Asumsi

1) Uji normalitas

Berdasarkan hasil analisis data menggunakan uji Kolmogorov-Smirnov satu sampel, diperoleh hasil seperti pada tabel 4 berikut: nghasilkan bentuk pola pencar yang tidak membentuk suatu pola tertentu

3) Uji linearitas

Dalam analisis regresi linear ganda, model yang telah ditentukan harus bersifat linier. Pemeriksaan linearitas dilakukan me-

Tabel 4. Hasil uji normalitas

\begin{tabular}{|c|c|}
\hline Variabel & Signifikansi \\
\hline Interaksi Sosial & 0,685 \\
\hline Berpikir Kritis & 0,370 \\
\hline Hasil Belajar Matematika & 0,359 \\
\hline
\end{tabular}

Dengan taraf signifikansi statistik yang digunakan sebesar 5\% berarti nilai taraf signifikansi statistik lebih dari taraf signifikansi pengujian sehingga dapat disimpulkan bahwa data untuk setiap variabel berdistribusi normal.

2) Uji homogenitas lalui uji linearitas.garis regresi. Setiap variabel memiliki nilai signifikansi linearity sebesar 0,000 yang berarti analisis regresi linier dapat digunakan untuk mencari pengaruh antara variabel bebas dan variabel terikat. 
Tabel 5. Hasil uji linearitas

\begin{tabular}{|c|c|c|}
\hline Signifikansi & Linearity & $\begin{array}{c}\text { Deviation of } \\
\text { linearity }\end{array}$ \\
\hline Interaksi sosial & 0,000 & 0,648 \\
\hline Berpikir kritis & 0,000 & 0,143 \\
\hline
\end{tabular}

\section{4) Uji Multikolinieritas}

Uji multikolonieritas dilakukan dengan melihat nilai Tolerance dan VIF (Variance Inflation Factor). Pada tabel 6 dapat dilihat bahwa nilai VIF untuk variabel interaksi sosial dan berpikir kritis adalah 1,002 yang berarti nilai VIF untuk kedua variabel kurang dari 10, maka dapat disimpulkan bahwa tidak terjadi multikolinieritas antara kedua variabel bebas. regresi dugaan tidak melalui titik pangkal, sehingga ada nilai $Y$ yang bernilai negatif. Oleh karena itu, untuk mendapatkan nilai $Y$ positif maka persamaan regresi dugaan hanya layak digunakan pada nilai-nilai $X_{1}, X_{2}$, dan $X_{3}$ yang menghasilkan nilai $Y$ positif.

Berdasarkan hasil analisis pada tabel 7 diperoleh nilai koefisien determinasi $\left(\mathrm{R}^{2}\right)$ sebesar 0,321. Daya ramal model ditunjukkan oleh koefisien determinasi sebesar

Tabel 6. Hasil perhitungan multikolinearitas

\begin{tabular}{|c|c|}
\hline Variabel & VIF \\
\hline Interaksi Sosial & 1,002 \\
\hline Berpikir Kritis & 1,002 \\
\hline
\end{tabular}

\section{b. Uji Hipotesis}

Berdasarkan hasil analisis uji hipotesis penelitian menggunakan analisis regresi linier ganda (tabel 7) diperoleh $b_{0}=-54,172 ; b_{1}=0,872 ;$ dan $b_{2}=$ 0,554 . Nilai $b_{0}$ adalah konstanta pada persamaan model regresi dugaan, $b_{1}$ dan $b_{2}$ masing-masing adalah koefisien untuk variabel $X_{1}$ dan $X_{2}$ sehingga model regresi dapat disusun menjadi

$$
\widehat{Y}=-54,172+0,872 X_{1}+0,554 X_{2}
$$

Karena taraf signifikansi statistik $(0,000)$ kurang dari taraf signifikansi pengujian $(0,05)$ sehingga dapat disimpulkan bahwa terdapat pengaruh antara variabel interaksi sosial dan berpikir kritis secara bersama-sama terhadap hasil belajar matematika siswa. Sedangkan untuk statistik $t$ bernilai signifikan maka persamaan
0,321 yang berarti bahwa $32,1 \%$ variasi nilai variabel terikat dapat dijelaskan oleh model.

1) Pengaruh interaksi sosial terhadap hasil belajar matematika

Taraf signifikasi untuk koefisien interaksi sosial sebesar 0,000. Hal ini menunjukkan terdapat pengaruh yang signifikan antara interaksi sosial secara parsial terhadap hasil belajar matematika siswa, atau dengan kata lain semakin tinggi interaksi sosial siswa maka semakin tinggi pula hasil belajar matematika siswa tersebut.

2) Pengaruh berpikir kritis terhadap hasil belajar matematika

Taraf signifikansi untuk koefisien berpikir kritis sebesar 0,000. Hal ini 
menunjukan terdapat pengaruh yang signifikan antara berpikir kritis secara parsial terhadap hasil belajar matematika. belajar matematika siswa yang diperoleh juga rendah.

Tabel 7. Hasil analisis regresi linier ganda

\begin{tabular}{|c|c|c|c|c|}
\hline Variabel & $\begin{array}{c}\text { Koef. } \\
\text { Regresi }\end{array}$ & $\mathbf{t}_{\text {hit }}$ & Sig. & $\begin{array}{c}\text { Koef. Determinasi } \\
\text { Parsial }\end{array}$ \\
\hline Konstanta & $-54,172$ & $-3,175$ & 0,002 & 0,290 \\
\hline Interaksi Sosial & 0,872 & 4,761 & 0,000 & 0,501 \\
\hline Berpikir Kritis & 0,554 & 8,235 & 0,000 & 0,566 \\
\hline $\mathrm{R}$ & \multicolumn{3}{|c|}{0,321} \\
\hline $\mathrm{R}^{2}$ & \multicolumn{3}{c|}{0,000} \\
\hline Probabilitas & \multicolumn{3}{c}{43,433} \\
\hline $\mathrm{F}_{\text {hit }}$ & \multicolumn{3}{c}{} \\
\hline
\end{tabular}

\section{B. Pembahasan}

Berdasarkan hasil analisis data diperoleh persamaan regresi dugaan adalah

$$
\widehat{Y}=-54,172+0,872 X_{1}+0,554 X_{2}
$$

Hal ini diartikan bahwa setiap penambahan 1 point pada interaksi sosial akan menambah hasil belajar matematika siswa sebesar 0,872 dengan asumsi variabel lain konstan; dan setiap penambahan 1 point pada kemampuan berpikir kritis akan menambah hasil belajar matematika sebesar 0,554 dengan asumsi variabel lain konstan.

Dari hasil analisis data di atas diperoleh bahwa antara variabel interaksi sosial, dan berpikir kritis baik secara bersama-sama maupun secara terpisah memiliki pengaruh positif terhadap hasil belajar matematika. Secara bersama-sama variabel interaksi sosial dan berpikir kritis mempengaruhi hasil belajar matematika pada materi Statistika sebesar 32,1\% sisanya sebesar $67,9 \%$ dipengaruhi faktor lain di luar penelitian. Hal ini menunjukkan bahwa hasil belajar matematika siswa dapat meningkat jika siswa mempunyai interaksi sosial, dan berpikir kritis matematika yang tinggi. Begitu pula sebaliknya jika interaksi sosial, dan berpikir kritis rendah maka hasil
Berdasarkan hasil analisis diketahui bahwa variabel interaksi sosial memiliki pengaruh positif terhadap hasil belajar matematika siswa. Hal ini terlihat dari taraf signifikasi statistik yang diperoleh nilainya kurang dari taraf signifikasi pengujian, yaitu $0,000<0,005$ dengan koefisien regresi ganda untuk variabel interaksi sosial 0,872 yang artinya setiap peningkatan percaya diri sebesar 1 satuan maka skor hasil belajar matematika juga meningkat sebesar 0,872.

Berdasarkan penelitian selain interaksi sosial, berpikir kritis juga berpengaruh terhadap hasil belajar matematika siswa. Hal ini terlihat dari taraf signifikasi statistik berpikir kritis nilainya kurang dari taraf signifikasi pengujian, yaitu $0,000<0,050$. Secara umum terlihat bahwa mayoritas responden memiliki kemampuan berpikir kritis dalam kategori sedang dengan ratarata 47,637 yaitu sebanyak 59 siswa berada pada kategori sedang dan 54 siswa berada pada kateogri berpikir kritis tinggi yang faktanya secara empiris berpengaruh positif terhadap hasil belajar matematikanya. Siswa dengan berpikir kritis yang baik maka akan lebih baik hasil belajar 
matematikanya. Namun sebaliknya, siswa dengan kategori berpikir kritis yang rendah maka hasil belajar matematikanya akan rendah pula.

Hasil penelitian ini juga sejalan dengan penelitian yang dilakukan oleh $\mathrm{Ai}$ Nuraida, Momoh Halimah, dan Ade Rokhyati tentang pengaruh interaksi sosial terhadap aktivitas belajar siswa kelas VI SD Negeri Salebu Kecamatan Mangunreja. Hasil penelitiannya juga menunjukkan bahwa interaksi sosial memiliki pengaruh sebesar $64,5 \%$ dan sisanya $34,6 \%$ dipengaruhi faktor lain di luar penelitian.

Interaksi sosial siswa SMP Negeri 1 Samarinda dikategorikan sedang dengan rata-rata skor 90,278. Berdasarkan penelitian yang telah dilakukan berkaitan dengan interaksi sosial siswa, terlihat bahwa siswa cendrung tergolong sedang, yaitu 76 siswa sedang sedangkan 51 siswa tinggi, walaupun masih ada siswa yang mempunyai tingkat interaksi sosial yang rendah. Interaksi sosial yang kurang baik tersebut ditunjukkan dengan jarangnya siswa menyampaikan pendapat atau bertanya saat proses belajar mengajar matematika di kelas, kurangnya komunikasi dua arah antara guru dan siswa.

Berdasarkan penelitian selain interaksi sosial, berpikir kritis juga berpengaruh terhadap hasil belajar matematika siswa. Hal ini terlihat dari taraf signifikasi statistik berpikir kritis nilainya kurang dari taraf signifikasi pengujian, yaitu $0,000<0,050$. Sementara itu, koefisien regresi untuk variabel berpikir kritis adalah 0,554 yang artinya setiap penambahan berpikir kritis sebesar 1 satuan maka hasil belajar matematikanya juga meningkat sebesar 0,554 satuan dengan skor interaksi sosial tetap.

Secara umum terlihat bahwa mayoritas responden memiliki kemampuan berpikir kritis dalam kategori sedang dengan rata-rata 47,637 yaitu sebanyak 59 siswa berada pada kategori sedang dan 54 siswa berada pada kateogri berpikir kritis tinggi yang faktanya secara empiris berpengaruh positif terhadap hasil belajar matematikanya. Siswa dengan berpikir kritis yang baik maka akan lebih baik hasil belajar matematikanya. Sebaliknya, siswa dengan kategori berpikir kritis yang rendah maka hasil belajar matematikanya akan rendah pula.

Penelitian ini menunjukkan bahwa ternyata interaksi sosial dan berpikir kritis setiap siswa berbeda-beda, sehingga perlu adanya perlakuan berbeda-beda kepada masing-masing siswa. Untuk siswa yang masih berada pada kategori berpikir kritis matematika rendah, hendaknya guru mampu memberikan motivasi kepada siswa dan memberikan sisi lain yang menarik dalam matematika agar siswa lebih mudah memahami dan tertarik dalam pembelajaran matematika sehingga diharapkan akan lebih mudah mencerna dan menganalisis serta memecahkan persoalan matematika. Untuk siswa yang berada pada kategori sedang dan tinggi, guru hendaknya memberikan bimbingan dan memberikan semangat agar siswa terus berpacu untuk belajar matematika dan jangan sampai siswa berhenti atau merasa puas pada tingkat ini. Siswa pada kategori sangat tinggi membutuhkan guru sebagai pendamping agak siswa tersebut tidak merasa jenuh mengikuti pelajaran dan dapat mencapai hasil yang maksimal. 


\section{KESIMPULAN}

Dari hasil penelitian telah ditemukan bahwa terdapat pengaruh interaksi sosial dan berpikir terhadap hasil belajar matematika siswa kelas VIII SMP Negeri 1 Samarinda tahun Ajaran 2017/2018.

\section{DAFTAR PUSTAKA}

Ai Nuraida, Momoh Halimah, dan Ade Rokhayati. (2014). Pengaruh Interaksi Sosial Terhadap Aktivitas Belajar Siswa Kelas VI SD Negeri Salebu Kecamatan Mangunreja. Jurnal PEDADIDAKTIKA: Jurnal Ilmiah Pendidikan Guru Sekolah Dasar, Vol. 1, No. 1 (2014).

Aunurrahman, D. (2012). Belajar dan Pembelajaran. Bandung: Alfabeta.

Dina, M. (2009). Suatu Alternatif Pembelajaran Kemampuan Berpikir Kritis Matematika. Jakarta: Cakrawala Maha Karya.

Herimanto dan Winarno. (2013). Ilmu Sosial dan Budaya Dasar. Jakarta: Bumi Aksara.

Indrati Endang Mulyaningsih. (2014). Pengaruh Interaksi Sosial Keluarga,
Motivasi Belajar, dan Kemandirian Belajar terhadap Prestasi Belajar. Jurnal Pendidikan dan Kebudayaan, vol. 20, no.4 (2014), pp. 441 - 451.

Iskandar. (2009). Psikologi Pendidikan (Sebuah Orientasi Baru). Jakarta: Gaung Persada (GP) Press.

Mulyati. (2005). Psikologi Belajar. Yogyakarta: Andi.

Mulyono, A. (2012). Anak Berkesulitan Belajar, Teori, Diagnosis, dan Remediasinya. Jakarta: Bumi Aksara.

Sanja Maričić, Krstivoje Špijunović, and Bojan Lazić. (2016). The Influence of Content on the Development of Students' Critical Thinking in the Initial Teaching of Mathematics. Croation Journal of Education, Vol. 18; No. 1/2016, pages: 11-40. Doi: 10.15516/cje.v18i1.132.

Sardiman. (2004). Interaksi dan Motivasi Belajar Mengajar. Jakarta: Raja Grafindo Persada.

Slameto. (2013). Belajar Dan FaktorFaktor Yang Mempengaruhinya. Jakarta: Rineka Cipta. 
| Jurnal PRIMATIKA, Volume 8, Nomor 2, Desember 2019

82 Pengaruh interaksi sosial dan berpikir kritis

Pratiwi Kurnia Sari - Sugeng 